\title{
THE CYSTIC ARTERY: AN OBSERVATIONAL STUDY AND CLINICAL SIGNIFICANCE OF ITS VARIANTS
}

Shilpa ${ }^{1}$, D. Saxena ${ }^{* 2}$, Shabina ${ }^{3}$.

${ }^{1,3} \mathrm{PhD}$ scholar, Department of Anatomy, S.M.S. Medical College \& Hospital, Jaipur (Rajasthan), India.

${ }^{* 2}$ Professor, S.M.S. Medical College \& Hospital, Jaipur, (Rajasthan), India.

\section{ABSTRACT}

Background: Cystic artery variations are frequent and important for invasive as well as invasive procedure around the hepatibiliary area. Variation can be in term of origin, course and termination of CA.

Aim: Aim was to identify new type of Cystic arterial variation in term of origin, no. of CA, and termination and surgical implications of these variations.

Materials and methods: Study was carried out at department of anatomy, S.M.S Medical college and hospitals Jaipur (Raj). Total 60 cadaver were included in the study. Ethical clearance was taken for the same. Subjects with history of abdominal surgery around Hepatobiliary area were excluded.

Result: Source of origin of SCA was RHA (majority of cases), Aberrant RHA, SMA, HAP. DCA was observed in $13.34 \%$ cases. Accessory CA arose from RHA, ARHA, HAP, PSPD. Compound DCA was observed in $5 \%$ cases. Longer CA was observed in the study.

Conclusion: Variation related to CA are essential to keep in mind while dealing with Hepatobiliary area during invasive and non invasive procedures as well.

KEY WORDS: Cystic, Hepatobiliary, Cystic arterial variation.

Corresponding Author: Dr. Dhiraj Saxena, Professor, Department of Anatomy, S.M.S. medical college and hospitals, (Rajasthan), India-302004. Contact no. -8076026920

E-Mail: shilpakayamkhani@gmail.com

Access this Article online

Quick Response code

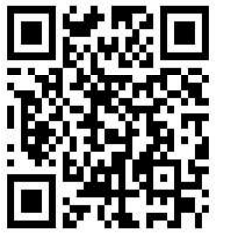

DOI: $10.16965 /$ ijar.2020.223

Journal Information

International Journal of Anatomy and Research

ISSN (E) 2321-4287 | ISSN (P) 2321-8967

https://www.ijmhr.org/ijar.htm

DOI-Prefix: https://dx.doi.org/10.16965/ijar



Article Information

Received: 19 Sep 2020

Peer Review: 20 Sep 2020

Revised: None
Accepted: 09 Oct 2020

Published (O): 10 Nov 2020

Published (P): 10 Nov 2020

\section{INTRODUCTION}

Cystic artery arises from Right hepatic artery which is main arterial supply to biliary system along with left hepatic artery. Cystic artery arises inside the Calot's triangle usually. It supplies oxygenated blood to the Gallbladder and Cystic Duct. Before supplying Gall Bladder, it divides into superficial branch for peritoneal surface of GB and deep branch for non peritoneal surface of $G B$.

Cystic artery is single usually but double CA can be found. Origin \& course of artery is also variable. This is most commonly injured artery during cholecystectomy due to frequent variations. Hemorrhage could be a problem during search of the CA if these variations are overlooked and that increases the rate of conversion to open surgery [1].

Gallbladder develops from hepatic diverticulum, which receives blood from coeliac trunk and superior mesenteric artery. Most of the vessels disappear during development, leaving mature vascular structure. Complex degeneration process leads to origin and branching 
pattern of the vessels to this organs also vary considerably variable [2].

It also needs to be kept in mind that, during laparoscopic visualization, anatomical relations are seen differently compared to conventional cholecystectomy [3].

This emphasizes the importance of cystic arterial dissection and necessity of thorough knowledge of cystic arterial variations for safe performance of cholecystectomy [1]

Aim of the study was to identify variation in term of origin, no. and course of CA.

\section{MATERIALS AND METHODS}

This was an observational study carried out in department of Anatomy in our institute. 60 cadavers were included without history of abdominal surgery. Ethical clearance was obtained for the same from ethical committee of the institute.

The study followed by cadaveric dissection of Hepatobiliary area. Precise meticulous dissection was done to prevent injury to the Hepatobiliary area. All variations were noted and photographs were taken for the same. Measurements were taken with help of measuring scale \& Vernier caliper. Origin and course was noted for CA.

\section{RESULTS}

Single CA was observed in $52(86.66 \%)$ cadaver, Double CA was noted in $8(13.34 \%)$ cadaver Out of 52 SCA, 34 SCA originated inside Calot's triangle, rest (18) was originated outside the triangle.(Table 1)

CA those arose outside the triangle,10(16.67\%) of them Enters in the triangle passing anterior to Common Hepatic Duct/Common Bile Duct and $8(13.33 \%)$ cases it passed anterior to Cystic Duct (fig.2).

Cystic artery (SCA) originated from Right hepatic artery in majority of case (75\%).in 8.34\% case had origin from hepatic artery proper (HAP),6.67\% SCA arose from Sup. Mesenteric artery. In $8.34 \%$ case of SCA originated from Aberrant RHA (named as Replaced RHA in few literature) (Table 2). 1.67\% cases had CA arising from common hepatic artery.
Length of CA was observed between $4 \mathrm{~mm}$ to $52 \mathrm{~mm}$.average length was $23.85 \mathrm{~mm}$ observed.(Table 3, bar chart.1)

Width of CA was ranged from 0.17 to $5 \mathrm{~mm}$. more than $50 \%$ cases were falling into $2-4 \mathrm{~mm}$ group. Average diameter was $2 \mathrm{~mm}$ observed. (Table 4, Bar chart:2)

Accessory CA was found in $13.33 \%$ cases. 6.67 case of ACA has origin from RHA, 3.34\% ACA arose from HAP,(fig.1) in 1.67 cases had ARHA (fig.3) origin. In $1.67 \%$ cases ACA arose from Posterior Superior Pancreatico Duodenal artery. (Table 2)(fig2)

$5 \%$ cases had both arteries arose inside Calot's triangle, compound DCA (fig.1) was found in $5 \%$ case whereas both arteries arose outside(fig.2) the triangle in $3.34 \%$ cases.

In one case of SCA, SCA from RHA outside the triangle passes anterior to $\mathrm{CHD}$ and divides into superficial br. and deep branch at joining of Cystic duct with CHD.

Table 1: No. and distribution of $C A$ in respect with Calot's Triangle.

\begin{tabular}{|c|c|c|c|}
\hline & Total no n (\%) & $\begin{array}{c}\text { Origin Inside the } \\
\text { Calot's Triangle n } \\
\text { (\%) }\end{array}$ & $\begin{array}{c}\text { Origin Outside } \\
\text { the Triangle } n(\%)\end{array}$ \\
\hline Single CA & $52(86.67)$ & $34(56.67)$ & $18(30)$ \\
\hline \multirow[t]{2}{*}{$\begin{array}{l}\text { Double } \\
\text { 1. ACA } \\
\text { 2. Main CA }\end{array}$} & $8(13.34)$ & $4(6.67)$ & $4(6.67)$ \\
\hline & & $5(8.34)$ & $3(5)$ \\
\hline
\end{tabular}

Table 2: Source of origin of CA \& ACA.

\begin{tabular}{ccc}
\hline Source of origin & CA $n$ (\%) & ACA $n$ (\%) \\
\hline RHA & $45(75)$ & $4(6.67)$ \\
\hline SMA & $4(6.67)$ & 0 \\
\hline HAP & $5(8.34)$ & $1(1.67)$ \\
\hline CHA & $1(1.67)$ & 0 \\
\hline Ab RHA & $5(8.34)$ & $2(3.34)$ \\
\hline PSPD & 0 & $1(1.67)$ \\
\hline
\end{tabular}

Table 3: frequency of different group of length of CA.

\begin{tabular}{ccccccc}
\hline Length $(\mathrm{mm})$ of CA & $0-10$ & $11-20$ & $21-30$ & $31-40$ & $41-50$ & $51-60$ \\
\hline No of Cadaver & 4 & 24 & 18 & 10 & 3 & 1
\end{tabular}

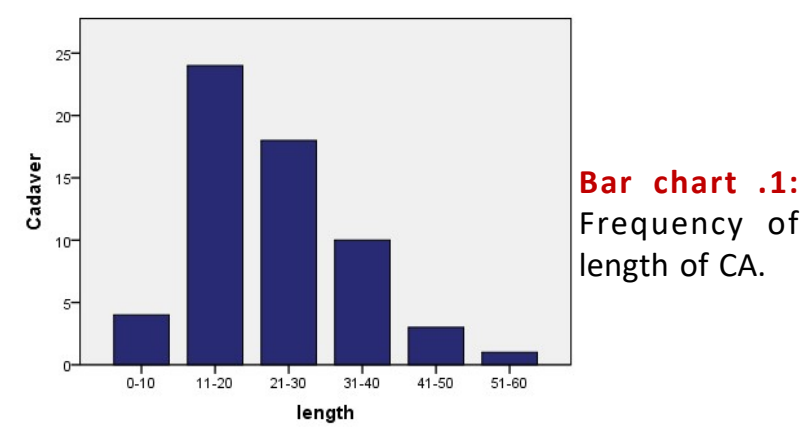


Table 4: Frequency of different group of Diameter of CA.

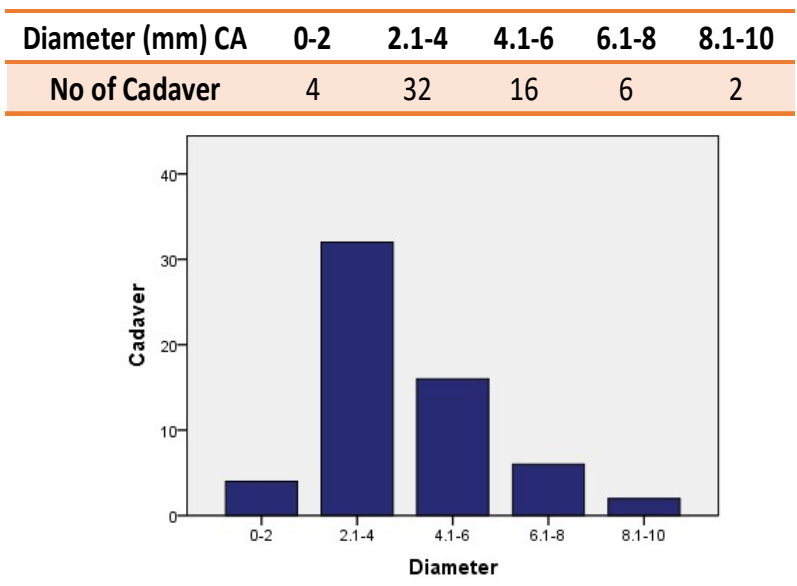

Bar chart.2: frequency of Diameter $(\mathrm{mm})$ of CA.

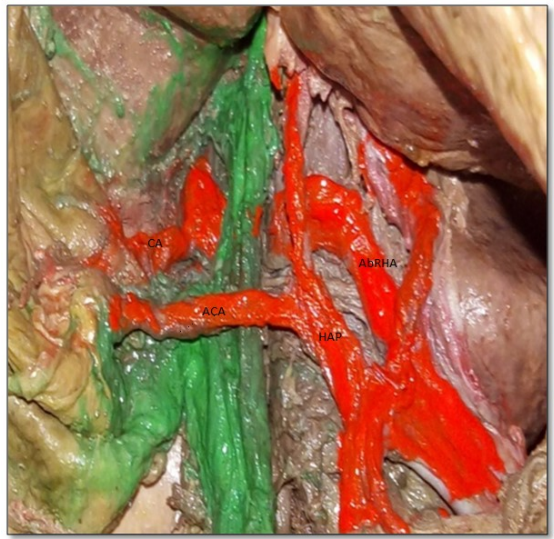

Fig. 1: ACA arising from HAP (origin-CHA), CA arose from AbRHA.



Fig. 2: DCA, one CA arising from pancreatico-duodenal artery, both arteries passes inferiorly, parallel to $\mathrm{CHD}$ and $C B D$ respectively. -Source of ACA-posterior sup pancreatico-duodenal artery

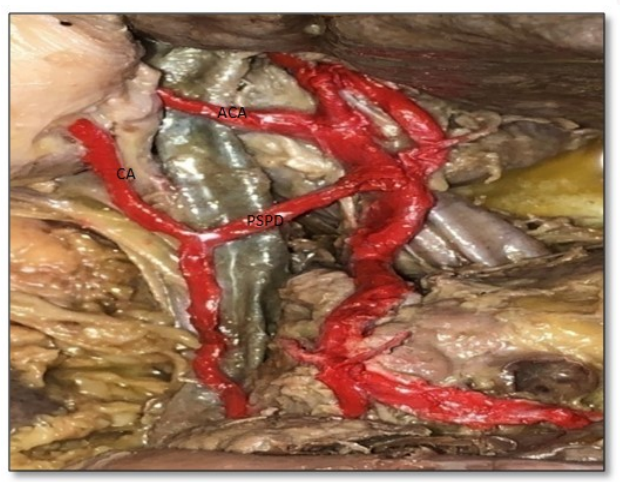

Fig. 3: ACA from ARHA

\section{DISCUSSION}

"Variation is rampant." Phrase by Sir Arthur Keith for biliary area is altered to read "variation is constant," [3] is befitting for cystic artery because of variation in its origin, no., \& course.

Single CA was observed in present case $86.67 \%$. This finding is consistent with Bhanasali SK [5] (2003) \& other authors who describes single CA in $80-85 \%$ cases $[6,7]$.

In $56.67 \%$ subject single CA was originated inside the triangle. Which was in concordance with Ramakrishna R [8] and Dandekar [1] reported similar in $\sim 60 \%$ cases.

In case of origin of CA outside Calot's triangle, CA passes anterior to CHD/CBD in $16.67 \%$ cases, which is similar to studies done by Andall et al. [9]. There study reported cystic artery passing anterior to the CHD in $17.9 \%$ cases. Daseler [10] reported similar incidence in $20 \%$ cases.

CA was situated anterior to CD in $13.91 \%$ case and superomedial to CD in86.67 \% cases. This is in concordance with findings of Sing'ombe [11] in Zambian population. They observed 93.7\% cadavers had the cystic artery superomedial to the cystic duct.

In case where Cystic artery lies anterior to bile duct it is first structure to be exposed during cholecystectomy, which makes it susceptible to injury [12]. Anterior course of CA is more prone to injury during cholecystectomy. Anterior to $C D, C B D$ and $C H D$ mar cause chances of injury to these ducts.

Cystic artery originated from RHA in $75 \%$ case in the present study, which is similar to findings of Daseler [12] \& Michels N A [4]. Observation related to CA originating from HAP is similar to findings of Flinski et al. [13] Higher incidence of CA originating from SMA observed in the study, similar to reported by Kankhare et al [14] with 5\%of population. Various case of origin from SMA have been reported (0.1$5 \%)$ in previous studies $[10,15]$.

CA arising from SMA normally passes behind pancreas and may course behind the Duodenum. one must be careful while performing invasive procedure in this area. Incidence of 
CA arising from ARHA was $8.34 \%$ in present study which is similar to Dandekar et al [1] variable result have been reported for ARHA from .9-16 in literature $[10,16]$.

Knowledge of abnormal source of origin of CA is must to avoid injury to the artery, as it originates outsides the calot's triangle in this case. Higher incidence of variability of origin of CA can be best understood on the basis of development. During development hepatic diverticulum is supplied by branches of aorta. With the time most of the branches degenerates leaving few nearer branches to supply the duct system. But degeneration is highly variable that clarify different source of origin of CA.

Length of Cystic artery was ranged from $4-52 \mathrm{~mm}$ in present study. Incidence of short CA $(<1)$ was found in $6.67 \%$ cadaver which is similar Taimur et al. [17], They found short CA in $7 \%$ population. Length range between $1-3 \mathrm{~cm}$ was found in $70 \%$ cadaver that coincides with study of Dandekar et al. [1], they found this incidence in $73 \%$ population. Longer CA found in $23.33 \%$ cadaver in present study which is similar to finding of Singombe et al. [11], They found long CA $(>4 \mathrm{~cm})$ in $21.9 \%$ population. This is higher than reported in previous studies $[1,17]$.

Average length of CA was observed $23.85 \mathrm{~mm}$ in present study which is similar to reported by Marniok et al. [18]. Longer or abnormally shorter CA indicates abnormal origin and course of artery. It must not be confused for other arteries in this area.

Diameter of CA ranged between .1-5 which coincides with that of Dandekar et al [1]. Diameter was more in present study than previously reported literature. Widest CA was of $5 \mathrm{~mm}$ size which is similar to reported by Polguj [19]-5.1mm.

Presence of Double CA in present study (13.34\%) was in accordance with Balija et al. [20], they documented double cystic artery in $13.6 \%$ population in their study on Western communities of Slovenians.

Compound CA was found in 3 cases $(5 \%)$ cases. Similar to this N Qamar [21] reported CCA in $5.33 \%$ cases. Zubair [15] reported in $5.46 \%$
Suzuki [22] in 7.3\% cases. Ding et al. [23] named cases where the cystic arteries existed not only in the Hepatobiliary triangle, but also outside it, i.e. the compound cystic artery type. They found $1.55 \%$ case with compound CA. Singh $\mathrm{H}$. [24] reported incidence of compound CA in $1 \%$ population who underwent laparoscopic cholecystectomy.

Double CA arising from RHA was found in Calot's Triangle in $6.67 \%$ cases in present study Antonetti and Diaz [25] reported DCA in 7.3\% case which is similar to present study, which is contrary to observed by Singh et al .they observed similar in $2.64 \%$ cases [26].

ACA originating from HAP was observed in $1.67 \%$ case which is similar to reported by Dandekar et al [1]. They observed similar case in $1.2 \%$ cases. Bincy MG et al [27] reported a case of double cystic artery and both arteries arose from the HAP.

Dolenšek [28] reported origin of ACA from ARHA which arose from SMA. In present case source of ARHA was SMA\& CHA in two different cases. Loukas et al. [29] double cystic arteries originating both from Right hepatic artery and the PSPD artery. Similar case was reported in present study also. If ACA remain unidentified, it is prone to injury [1].

Knowledge of variation of CA is important because unrecognized cause of bleeding during cholecystectomy may lead to conversion in open surgery in $1.9 \%$ case and mortality in .02\% [9].

\section{CONCLUSION}

In term of origin and course of CA, its frequent variations need to keep in mind while dealing with Hepatobiliary area, or it may lead to hemorrhage succeeded by injury to biliary duct also and may increase chances of injury to duct system also.

\section{ABBREVIATION}

CD- cystic duct

CHD- common hepatic duct

CBD-common bile duct

CA- cystic artery

AbRHA- aberrant right hepatic artery

ARHA- accessory right hepatic artery

SMA- superior mesenteric artery

PSPD-posterior superior pancreatico duodenal artery 
HAP- hepatic artery proper

CHA- common hepatic artery

SCA- single cystic artery

DCA- double cystic artery

Conflicts of Interests: None

\section{REFERENCES}

[1]. Dandekar U, Dandekar K.Cystic Artery: Morphological Study and Surgical Significance Anatomy Research International Volume. 2016;Article ID 7201858. 6 pages

https://doi.org/10.1155/2016/7201858

PMid:27822387 PMCid:PMC5086348

[2]. Hiatt JR, Gabbay J, Busuttil RW. Surgical anatomy of the hepatic arteries in 1000 cases. Ann Surg 1994;220(1):50-52. https://doi.org/10.1097/ 00000658-199407000-00008

PMid:8024358 PMCid:PMC1234286

[3]. A. K. Sarkar and T. S. Roy.Anatomy of the cystic artery arising from the gastroduodenal artery and its choledochal branch- a case report. J. Anat.2000;197(3):503-506. https://doi.org/ 10.1046/j.1469-7580.2000.19730503.x

PMid:11117634 PMCid:PMC1468149

[4]. Michel NA.: Variational anatomy of the hepatic, cystic and retroduodenal arteries; statistical analysis of their origin, distribution and relations to the biliary ducts in 200 bodies. Arch. Surg.1953;66:20. https://doi.org/10.1001/archsurg.1 953.01260 030031003 PMid:12996197

[5]. Bhanasali SK. Extra-heptic biliary tree. In editors: Hai AA, Shrivastava RB. Textbook of surgery. Tata McGraw Hill Publishing Company, New Delhi, 2003. p. 554

[6]. Haythem A. Al-Sayigh.The Incidence of Cystic Artery Variation during Laparoscopic Surgery. Med J Babylon.2010;7:389-403.

[7]. Gupta RL. The gallbladder and bile duct: Text book of surgery. 2nd ed. Jaypee Brothers Medical Publishers (P) Ltd, New Delhi.2003:755.

[8]. Ramakrishna R,Tiwari S. Cystic Artery: An Anatomic Morphological Study and Its Clinical Significance Natl J Clin Anat. 2019;8:10-13. https://doi.org/10.1055/s-0039-1688516

[9]. Andall, R.G., Matusz, P., du Plessis, M. et al. The clinical anatomy of cystic artery variations: a review of over 9800 cases. Surg Radiol Anat .2016;38:529-539.

https://doi.org/10.1007/s00276-015-1600 PMid:26698600

[10]. Daseler EH, Anson BJ, Hambley WD, Reimann AF. The cystic artery and constituents of the hepatic pedicle: a study of 500 specimens. Surg Gynecol Obstet.1947;85(1):47-63.

[11]. Sing'ombe I.,Nambule V., Mutalif F., Mutemwa S.et al. cadaveric study on variations of the cystic artery in the department of pathology, at the university teaching hospitals, lusaka, Zambia.Anatomy Journal of Africa. 2019;8(1):1438-1443.
[12]. Hugh T. B., Kelly M. D., Li B. Laparoscopic anatomy of the cystic artery. Am.J.Surg. . 1992;163(6):593595.https://doi.org/10.1016/0002 9610(92)90564-8

[13]. Flisinski P, Szpinda M, Flisinski M. The cystic artery in human foetuses. Folia Morphol.2004; 63(1):4750.

[14]. Kankhare Sonali B, Patil Anjali D, Kate Sarika P. A study of an anomalous origin of cystic artery and its relation with calot's triangle - cadaveric study. Int J Cur Res Rev 2016;8(15):39-42.

[15]. Pushpalatha K., Shamasundar N. M. Variation in the origin of cystic artery. Journal of Anatomical Society of India. 2010;59(1):35-37. https://doi.org/10.1016/S0003-2778(10)80009-7

[16]. Zubair M,Habib L, Mirza MR,Channa MA, Yousuf $M$ et al.Anatomical Variations Of Cystic Artery: Telescopic facts. Med J Malaysia.2012;67(5) :494-96.

[17]. Taimur M, Hasan A, Ullah S, Masood R, Imran M. Vascular variations in the Calot's triangle seen on laparoscopic cholecystectomy. Pak Armed Forces Med J 2011;61(4):16-20.

[18]. Marniok B, Mikusek J,Wiewi M et al.Anatomical variations of cystic duct and artery in direct preparations. Med Sci Monit.1999; 5(3): 395-398.

[19].Polguj M, Podgo'rski M, Hogendorf P,Topol M.Variations of the hepatobiliary vasculature including coexistence of accessory right hepatic artery with unusually arising double cystic arteries: case report and literature review.Anat Sci Int. 2014; 89:195-198.

https://doi.org/10.1007/s12565-013-0219-5 PMid:24310410 PMCid:PMC4015057

[20].Balija M, Huis M, Nikolic V, Stulhofer M. Laparoscopic visualization of the cystic artery anatomy. World J Surg.1999; 23:703-707.

https://doi.org/10.1007/PL00012372 PMid:10390590

[21]. Qamar N, Ishaque I, Ilyas A, Parveen K, Zubair M, Ahmad S. Identification of cystic duct variations in laparoscopic visual field. Pak J Surg. 2016;32(2): 96-99.

[22]. Suzuki M, Akaishi S, Rikiyama T, Naitoh T,Rahman MM, Matsuno S. Laproscopic cholecystectomy, Calot's triangle, and Variations in cystic arterial supply. Surg. Endosc.2000;14:141-4.

https://doi.org/10.1007/s004649900086 PMid:10656947

[23]. DingYM, WangB, WangWX,Wang P, Ya JS. New classification of the anatomic variations of cystic artery during laparoscopic cholecystectomy. World J Gastroenterol .2007; 13(42): 5629-5634. https://doi.org/10.3748/wjg.v13.i42.5629 PMid:17948938 PMCid:PMC4172743

[24]. Singh H, Singh NK, Kaul RK, Gupta A. Prevalence of anatomical variations of cystic artery during laparoscopic cholecystectomy. Int Surg J. 2019;6(10):3781-3785.

https://doi.org/10.18203/2349-2902.isj20194441

[25].C. Antonetti and F. Diaz.Arteria c'ýstica: consideraciones anatomicas. RFM.2007;30(1):80-89. 
[26]. Singh K, Singh R, Kaur M. Clinical reappraisal of vasculobiliary anatomy relevant to laparoscopic cholecystectomy. J Min Access Surg 2017;13:2739. https://doi.org/10.4103/jmas.JMAS_268_16 PMid:28872096 PMCid:PMC5607794

[27]. Bincy MG, Somayaji SN.Multiple variations of the subhepatic hepatobiliary vasculature porta. Int J Anat Var.2010; 3:39-40.

[28]. Dolenšek J. Triple arterial blood supply to the liver and double cystic arteries: A case report.Folia morphologica 2015;76(3):523-26. https://doi.org/10.5603/FM.a2017.0008 PMid:28150275
[29]. Loukas M, Fergurson A, Louis RG Jr, Colborn GL. Multiple variations of the hepatobiliary vasculature including double cystic arteries, accessory left hepatic artery and hepatosplenic trunk: a case report. Surg Radiol Anat.2006;28:525-28. https://doi.org/10.1007/s00276-006-0138-4 PMid:17006621

How to cite this article:

Shilpa, D. Saxena, Shabina. THE CYSTIC ARTERY: AN OBSERVATIONAL STUDY AND CLINICAL SIGNIFICANCE OF ITS VARIANTS. Int J Anat Res 2020;8(4.1):7788-7793. DOI: 10.16965/ijar.2020.223 